\title{
Prior Invasive Malignancy of Other Sites
}

National Cancer Institute

\section{Source}

National Cancer Institute. Prior Invasive Malignancy of Other Sites. NCI Thesaurus. Code C154620.

A finding indicating the presence of a previously diagnosed malignant neoplasm infiltrating other, non-specified anatomic sites. 